\title{
A Study of Hypoalbuminemia and Pleural Effusionin Pediatric Nephrotic Syndrome
}

\author{
Tovan Perinandika, ${ }^{1}$ Dedi Rachmadi S, ${ }^{2}$ Fenny Dwiyatnaningrum, ${ }^{3}$ \\ ${ }^{1}$ Faculty of Medicine Universitas Padjadjaran, ${ }^{2}$ Department of Child Health Faculty of Medicine \\ Universitas Padjadjaran/Dr. Hasan Sadikin General Hospital Bandung, ${ }^{3}$ Department of Anatomy, \\ Cell Biology, and Physiology Faculty of Medicine Universitas Padjadjaran
}

\begin{abstract}
Background: Nephrotic syndrome (NS) is a kidney disease that is most often found in children. Hypoalbuminemia in NS can cause a decrease in oncotic pressure causing extravasation of fluid into the interstitial space. In conditions of severe hypoalbuminemia, fluid extravasation may cause occurrence of pleural effusion. The objectives of this study was to analyze the correlation between hypoalbuminemia and pleural effusion in children with NS.

Methods: An analytical study was conducted on 69 medical records of pediatric nephrotic syndrome from 1 January 2008-31 December 2013 in dr. Hasan Sadikin General Hospital. Inclusion criteria were pediatric patients between 1-14 years old with NS. Exclusion criteria were patients who already had albumin transfusion, malnutrition, patients with chronic disease, and incomplete medical record information. Contingency coefficient test was carried out to discover the correlation between variables.

Results: Out of 89 samples, 69 samples were included. Characteristics of the included patients are male $(n=48)$, female $(n=21)$, age 1-5 ( $n=24), 6-10(n=22), 11-14(n=23)$, mild hypoalbuminemia $(n=3)$, moderate hypoalbuminemia $(n=27)$, severe hypoalbuminemia $(n=39)$, patients with pleural effusion $(n=23)$, and nonpleural effusion $(\mathrm{n}=46)$. There was a significant correlation between hypoalbuminemia and pleural effusion with $\mathrm{p}=0.000(\mathrm{p}<0.05)$ and moderate correlation $(\mathrm{r}=0.437)$.
\end{abstract}

Conclusions: Hypoalbuminemia has correlation with pleural effusion in pediatric nephrotic syndrome.

Keywords: Hypoalbuminemia, pediatric nephrotic syndrome, pleural effusion.

\section{Introduction}

Nephrotic syndrome (NS) is a kidney disease that is most common in children. Nephrotic syndrome is characterized by massive proteinuria $(\geq 40 \mathrm{mg} / \mathrm{m} 2 \mathrm{LPB} / \mathrm{h}$ or $>50 \mathrm{mg} /$ $\mathrm{kg} / 24$ hours, or the ratio of albumin / creatinine in random urine $>2 \mathrm{mg} / \mathrm{mg}$, or dipstick $\geq 2+$ ), hypoalbuminemia $(<2,5 \mathrm{~g} / \mathrm{dl})$, edema, and accompanied by hypercholesterolemia $>200$ $\mathrm{mg} / \mathrm{dl}) .{ }^{1}$ At the Department of Child Health, Faculty of Medicine, Universitas Padjadjaran/ Dr. Hasan Sadikin General Hospital 241 patients with kidney disease were treated, comprising 129 cases of NS (53.5\%) with an average age of 6 years 4 months during January 1995 to June $1999 .{ }^{2}$

The chief complaint in patients with NS usually is edema. These symptoms appear due to a decrease in the levels of albumin in the blood which has the function to maintain oncotic pressure. When conditions of hypoalbuminemia occurs, oncotic pressure will drop, causing extravasation of fluid into the interstitial space or serousa cavity. ${ }^{3}$

Edema in patients with NS usually happens in the periorbital region, especially in the morning. As the day goes, periorbital edema will be reduced but edema pretibia will occur. If edema is getting worse, it will cause ascites or pleural effusion. For nephrotic syndrome, the most common is transudative pleural effusion. ${ }^{4}$

Pleural effusion can lead to hypoxic conditions so that oxygen carried to the tissues will be reduced. In children with chronic hypoxemia, the child will look small for his/ her age, suffer delayed cognitive and motor

Correspondence: Tovan Perinandika, Faculty of Medicine, Universitas Padjadjaran, Jalan Raya Bandung-Sumedang Km.21, Jatinangor, Sumedang, Indonesia, Phone: +628122041399 Email: p.tovan@yahoo.com 
development, shortness of breath on exertion, fatigue, and is not able to exercise. ${ }^{5,6}$ The aim of this study was to analyze the correlation between hypoalbuminemia and pleural effusion in pediatric nephrotic syndrome.

\section{Methods}

The study population was children with NS at Dr. Hasan Sadikin General Hospital. Data were derived from secondary data of medical records at Dr. Hasan Sadikin General Hospital from 1 January 2008-31 December 2013.

The process of data collection was carried out in October to November 2014 with approval from the Medical records departement and the Health Research Ethics Committee of the Dr. Hasan Sadikin General Hospital .

The inclusion criteria of this study were medical records of patients with SN and aged between 1-14 years. The exclusion criteria were medical records of patients which consisted of information that those patients had received an albumin transfusion, had poor nutritional status and suffered from chronic diseases such as pulmonary tuberculosis, malignancy, heart failure, hepatic cirrhosis, and chronic renal failure. In addition, medical records withincomplete data were also excluded. A total of 86 medical records were identified, but 17 samples were excluded so that only 69 medical records were accepted forthis study. The medical records that were excluded consisted of information about pulmonary tuberculosis $(\mathrm{n}=13)$, chronic renal failure $(n=1)$, and incomplete data $(n=3)$.

Furthermore, the age of the patients was categorized in 3 groups, namely aged 1-5 years, $6-10$ years and $11-14$ years. The degree of hypoalbuminemia value was categorized as mild $(2-2.5 \mathrm{~g} / \mathrm{dl})$, moderate $(2.5>-1.5 \mathrm{~g} / \mathrm{dl})$, and severe $(<1.5 \mathrm{~g} / \mathrm{dl})$. Moreover, the existence of pleural effusion was identified from chest $\mathrm{X}$-ray concluded in the medical records.

The collected data were statistically analyzed by using the contingency coefficient test.

\section{Results}

From 69 children with NS, the number of male patients exceeded female patients. The distribution of NS was similar in every age group. In terms of hypoalbuminemia, the number of patients with severe hypoalbuminemia were higher compared to those with mild hypoalbuminemia. The incidence of pleural effusion was lower compared to patients without pleural effusion.

Moreover, contingency coefficient test was performed on hypoalbuminemia and pleural effusion. Results of the analysis showed that there was a significant correlation (0.437) between the two variables with $\mathrm{p}=0.000$ ( $\mathrm{p}$ $<0.05$ ).

Table 1 Characteristics of Pediatric Nephrotic Syndrome

\begin{tabular}{|c|c|}
\hline Characteristics & Total $(n=69)$ \\
\hline \multicolumn{2}{|l|}{ Sex } \\
\hline Male & 48 \\
\hline Female & 21 \\
\hline \multicolumn{2}{|l|}{ Age (years old) } \\
\hline $1-5$ & 24 \\
\hline $6-10$ & 22 \\
\hline $11-14$ & 23 \\
\hline \multicolumn{2}{|l|}{ Hypoalbuminemia } \\
\hline Severe & 39 \\
\hline Moderate & 27 \\
\hline Mild & 3 \\
\hline \multicolumn{2}{|l|}{ Pleural effusion } \\
\hline No pleural effusion & 46 \\
\hline Pleural effusion & 23 \\
\hline
\end{tabular}




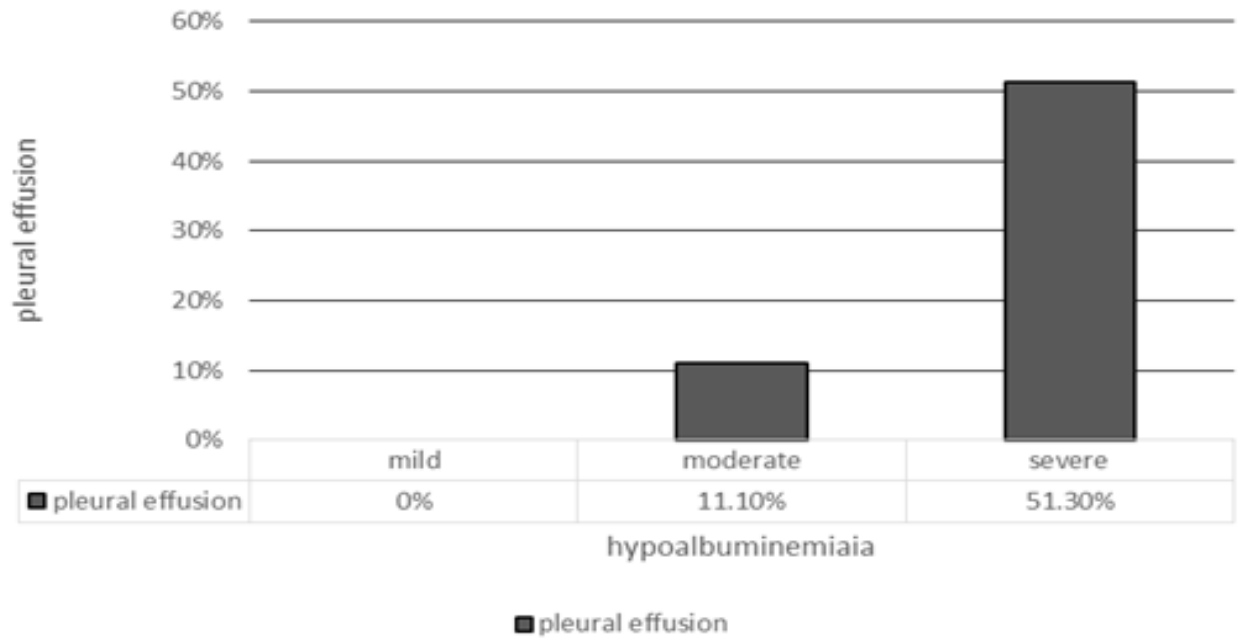

Figure 1 Percentage of pleural effusion in Hypoalbuminemia

\section{Discussion}

This study showed that there was a relationship between hypoalbuminemia and pleural effusion, but the strength of the correlation was moderate. Hypoalbuminemia is one of the causes of pleural effusion, especially transudative pleural effusion.7,8 In 1999, Alain Eid et al. ${ }^{9}$ conducted a similar study by connecting hypoalbuminemia and pleural effusion. The results showed hypoalbuminemia as a cause of pleural effusion, however it is a rare cause of pleural effusion because all studies with low serum albumin levels have at least one other potential disease in the study. Other clinical evaluation is necessary regarding the cause of pleural effusion in people with hypoalbuminemia. ${ }^{9}$

Based on the theory of Starling, fluid shifts from the intravascular to the interstitial space is influenced by several things, namely vascular permeability, intravascular hydrostatic pressure, hydrostatic pressure of the interstitial space, intravascular oncotic pressure and oncotic pressure of the interstitial space. Thus, hypoalbuminemia is a cause of pleural effusion because it can lower oncotic pressure in the blood so that the intravascular fluid moves into the cavity serosa. ${ }^{3}$ However, Siddall and Radhakrishnan ${ }^{3}$ stated that hypoalbuminemia does not cause edema and extravasation of fluid. Hypoalbuminemia conditions in parallel lead to decreasing levels of albumin in the interstitial spaces and interstitial hydrostatic pressure resulting in extravasation of fluid is constant and does not cause edema. Another possibility might be due to a disturbance in vascular permeability which causes the extravasation of fluid, but it is still not investigated further. ${ }^{3}$

Results of a study conducted Zaffanello and Franchini ${ }^{10}$ showed that chylothorax which is one type of pleural effusion can be caused by nephrotic syndrome, due to coagulation disorders caused by nephroticsyndrome. Kerlin et al. ${ }^{11}$ proved that the nephrotic syndrome is often followed by thromboembolism events. This causes of thromboembolism should always be considered in any event of nephrotic syndrome, associated with complications which is chylothorax.$^{11}$ Further studies should be conducted on the relationship between serum albumin levels and thrombus formation to determine the possible relationship between hypoalbuminemia and chylothorax.

Limitation of this study is that there is no differentiation type of pleural effusion because pleural effusion caused by nephrotic syndrome is transudative pleural effusion. If there was exudative pleural effusion, the effusion due to other causes could affect the results.

It can be concluded that there is a relationship between hypoalbuminemia and pleural effusion in children with nephrotic syndrome. Thus, it can also become a factor for clinicians to consider the incidence of pleural effusion in nephrotic syndrome children .

\section{References}

1. Trihono P, Alatas H, Tambunan T, Pardede S. Konsensus tata laksana sindrom nefrotik 
idiopatik pada anak. Unit Kerja Koordinasi Nefrologi Ikatan Dokter Anak Indonesia Jakarta: Badan Penerbit IDAI. 2008.

2. Ponco E. Hubungan kadar kolesterol total darah dengan frekuensi relaps pada anak dengan sindrom nefrotik di Bagian/SMF Ilmu Kesehatan Anak FKUP/RS Hasan Sadikin kurun waktu 1995-1999 [thesis]. Bandung: Universitas Padjadjaran. 1999.

3. Siddall EC, Radhakrishnan J. The pathophysiology of edema formation in the nephrotic syndrome. Kidney Int J. 2012;82(6):635-42.

4. Nilawati G. Profil sindrom nefrotik pada ruang perawatan anak RSUP Sanglah Denpasar. Sari Pediatri. 2012;14(4):26972.

5. Webster WS, Abela D. The effect of hypoxia in development. Birth Defects Res (Part C). 2007;81(3):215-28.

6. Liu L, Cash TP, Jones RG, Keith B, Thompson CB, Simon MC. Hypoxia-induced energy stress regulates mRNA translation and cell growth. Mol Cell J. 2006;21(4):521-31.

7. McGrath E, Barber C. Bilateral pleural effusions. Can Med Assoc J. 2010;182(17):1879-82.

8. Rehan M, Alam MT, Aurangzeb M, Imran K, Farrukh SZ, Masroor M. The frequency of various diseases in patients presenting with pleural effusion. Gomal J Med Sci. 2013;11(1):78-83.

9. Light RW. The undiagnosed pleural effusion. Clin Chest Med J. 2006;27(2):30919.

10. Zaffanello M, Franchini M. Thromboembolism in childhood nephrotic syndrome: a rare but serious complication. Hematology. 2007;12(1):69-73.

11. Kerlin BA, Blatt NB, Fuh B, Zhao S, Lehman A, Blanchong $\mathrm{C}$, et al. Epidemiology and risk factors for thromboembolic complications of childhood nephrotic syndrome: a Midwest Pediatric Nephrology Consortium (MWPNC) study. J Pediatr. 2009;155(1):105-10. 